\title{
Ocorrência e controle do pulgão-preto, Aphis craccivora Koch (Hemiptera: Aphididae), em mudas de jacarandá- do-cerrado (Dalbergia miscolobium Benth.) com o uso de detergente neutro
}

\author{
Marcelo Tavares de Castro ${ }^{\natural}$ \& Sandro Coelho Linhares Montalvão ${ }^{2}$
}

1. Centro Universitário ICESP de Brasília. 2. Embrapa Recursos Genéticos e Biotecnologia.

EntomoBrasilis 12 (3): 154-156 (2019)

\begin{abstract}
Resumo. Aphis craccivora Koch (Hemiptera: Aphididae), um afídeo altamente polífago e praga de muitas culturas de interesse econômico, é relatado pela primeira vez causando deformações na gema apical e nos folíolos novos de mudas de Dalbergia miscolobium Benth (Leguminosae) em Brasília, Distrito Federal, Brasil. Diferentes concentrações de soluções de detergente neutro e água foram testadas para controlar o afídeo, com o uso de nove mudas infestadas. Os afídeos foram previamente contados em cada planta e dois tratamentos foram utilizados (detergente neutro a $5 \%$ e 10\%), além da testemunha, onde só foi aplicado água. Ambas as doses causaram mortalidade e a concentração de $5 \%$ apresentou $83,8 \%$ de eficiência, o que indica que esse tratamento é eficaz para diminuir a população desses insetos em mudas de jacarandá-do-cerrado.
\end{abstract}

Palavras-Chave: Afídeo; Controle Alternativo; Entomologia Florestal; Fitófago; Praga.

Occurrence and control of the black aphid, Aphis craccivora Koch (Hemiptera: Aphididae), on "jacarandá-do-cerrado" seedlings (Dalbergia miscolobium Benth.) with the use of neutral detergent

Abstract. Aphis craccivora Koch (Hemiptera: Aphididae), a highly polyphagous aphid and pest of many economic crops, is reported for the firsttime causing deformations in the apical bud and on the new folioles of Dalbergia miscolobium Benth (Leguminosae) seedlings in Brasilia, Federal District, Brazil. Different concentrations of neutral detergent and water solutions were tested to control the aphid using nine infested seedlings. The aphids were previously counted in each plant and two treatments were used ( $5 \%$ and $10 \%$ of neutral detergent), and the control, where only water was applied. Both concentrations caused mortality and the $5 \%$ showed an efficiency of $83.8 \%$, which indicates that this treatment is effective to decrease the population of these insects in "jacarandá-do-cerrado" seedlings.

Keywords: Aphid; Alternative Control; Forest Entomology; Pest; Phytophagous.

(a) Cerrado lato sensu abrange aproximadamente $23 \%$ do território brasileiro e é o segundo maior bioma do país. Mendonça et al. (2008) relatam que a sua flora é composta por mais de 12 mil espécies de hábitos e ambientes variados. Porém, devido à expansão urbana e agrícola, invasão de espécies exóticas, ocorrência de erosões e degradação de ecossistemas entre outros fatores, estima-se que o Cerrado desapareça até 2030, caso medidas protetivas e sustentáveis não sejam tomadas (PREvEdello \& CARVALHO 2006). Com base nisso, a produção de mudas de espécies nativas desse bioma se torna imprescindível para que sejam usadas futuramente em programas de recuperação de áreas degradadas e de arborização urbana.

A espécie Dalbergia miscolobium Benth. (Leguminosae), conhecida popularmente como jacarandá-do-cerrado, é uma leguminosa típica do Cerrado, com ocorrência em oito Estados brasileiros e no Distrito Federal (Almeida et al. 1998). É uma árvore ornamental com alto potencial para o paisagismo e recuperação de áreas degradadas. Os frutos são utilizados no artesanato e sua madeira serve para confecção de pequenos objetos, como facas e enfeites, e também para a fabricação de móveis. Além disso, a casca fornece tinta que é usada pela população local para tingir tecidos (SILVA-JÚNIOR et al. 2012).

Até o presente momento, poucos organismos têm sido relatados causando danos em plantas de D. miscolobium. O fungo Phoma sp. é relatado como o principal problema fitossanitário da espécie, inclusive em mudas, na qual causa lesões necróticas foliares de cor preta, afetando a sobrevivência e o crescimento da planta (BRAZ et al. 2000; MARQUis et al. 2001). O fornecimento de mudas de qualidade, sem pragas e doenças, é essencial para que a implantação de arborização urbana e de recuperação de áreas degradadas obtenha sucesso.
Edited by:

William Costa Rodrigues

\section{Article History:}

Received:28.vii.2019

Accepted: 09.ix.2019
Corresponding author:

Marcelo Tavares de Castro

⿶ marceloengflorestal@gmail.com

(1) http://orcid.org/0000-0002-9147-8039
Funding agencies:

$\Delta$ Without funding declared 
Este trabalho teve como objetivo registrar a ocorrência de Aphis craccivora Koch (Hemiptera: Aphididae) em mudas de jacarandá-do-cerrado e testar duas concentrações de soluções de detergente neutro para o seu controle.

Afídeos infestando nove mudas de D. miscolobium foram observados em outubro de 2017 em Águas Claras, Distrito Federal, Brasil ( $15^{\circ} 85^{\prime} 35.2^{\prime \prime}$ S, $48^{\circ}$ O3'25.5” W). As mudas tinham aproximadamente seis meses de idade e estavam em saquinhos contendo uma mistura de solo e substrato (Plantmax $®$ ). Alguns insetos foram colocados em tubos Falcon contendo álcool $75 \%$ e enviados para identificação por uma especialista do Departamento de Proteção de Plantas da Universidade Estadual Paulista, São Paulo (FCAV/ UNESP).

Para os testes de controle do afídeo, foram utilizadas as

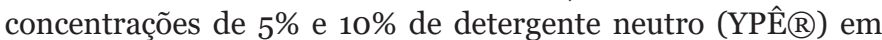
solução com água, com base nos resultados do trabalho de CYSNE et al. (2014), além da testemunha com apenas água. Foi feita uma única aplicação de cada tratamento e as contagens do número de pulgões foram feitas após dois e sete dias de aplicação. Os testes foram realizados com as mudas acondicionadas em uma casa de vegetação não-climatizada. Os dados obtidos foram submetidos à ANOVA e ao teste de Tukey $(\mathrm{p}<0.05)$ utilizando o programa estatístico Sisvar. A eficiência dos tratamentos foi calculada a partir da fórmula de Аввотт (1925) modificada.

As amostras de pulgões coletadas em $D$. miscolobium foram identificadas como $A$. craccivora, conhecido popularmente como pulgão-preto. Os insetos foram observados cobrindo grande parte dos ponteiros das mudas $(n=9)$, atacando as folhas e brotações apicais, causando deformações na gema apical e nos folíolos recém-emergidos, resultando em um aspecto encarquilhado. Além dos pulgões, formigas (Hymenoptera: Formicidae) foram encontradas em associação benéfica com os afídeos, conforme já relatado por STURZA et al. (2011) ao reportar a ocorrência de $A$. craccivora em diversas plantas daninhas. Sintomas causados pelo fungo Phoma sp. também foram observados nas mudas infestadas pelos pulgões.

Foram encontrados aproximadamente 1.700 indivíduos de A. craccivora durante a primeira avaliação nas nove plantas, na qual foi decaindo no decorrer do experimento nos dois tratamentos utilizados, conforme pode ser visualizado na Figura 1. Resultados semelhantes foram obtidos por IMENES et al. (2002) ao aplicar diferentes concentrações de detergente para o controle da cochonilha Protopulvinaria pyriformis Cockerell (Hemiptera: Coccidae) em Schefflera arboricola (Hayata) Merr. (Araliaceae), onde após 12 dias de aplicação dos tratamentos, houve um decréscimo na população desses insetos.

As aplicações das soluções de detergente a $5 \%$ e $10 \%$ apresentaram eficiências de $83,8 \%$ e $67,2 \%$, respectivamente (Tabela 1). Na primeira avaliação, após dois dias, houve diferença estatística entre os tratamentos testados, onde a solução de $5 \%$ se sobressaiu com relação aos demais. Esse resultado persistiu até a segunda e última avaliação, após sete dias. Portanto, o uso de detergente neutro na concentração de $5 \%$ foi expressivo em causar mortalidade nos pulgões.

O controle de A. craccivora é feito sobretudo com o uso de alguns produtos químicos (ANDREI 2009), especialmente com



Figura 1. Número total de indivíduos de Aphis craccivora nas mudas de Dalbergia miscolobium na primeira avaliação (antes da aplicação dos tratamentos) e após dois e sete dias da aplicação dos tratamentos.

Tabela 1. Número médio de indivíduos vivos de Aphis craccivora em mudas de jacarandá-do-cerrado após a aplicação de diferentes soluções de detergente neutro.

\begin{tabular}{ccccc}
\hline Tratamento & $\mathbf{1}^{\mathbf{0}}$ Contagem & 2 DAA & 7 DAA & Eficiência (\%) \\
\hline $5 \%(50 \mathrm{~mL} / \mathrm{L})$ & 186,3 & $49,6 \mathrm{a}$ & $34,6 \mathrm{a}$ & 83,8 \\
$10 \%(100 \mathrm{~mL} / \mathrm{L})$ & 226 & $114 \mathrm{~b}$ & $70,3 \mathrm{~b}$ & 67,2 \\
Testemunha & 198,6 & $205 \mathrm{c}$ & $214,6 \mathrm{c}$ & - \\
\hline
\end{tabular}

- DAA: dias após a aplicação.

- Médias seguidas da mesma letra não diferem entre si pelo teste de Tukey (5\%). 
acefato, um organofosforado. Assim, o uso de detergente neutro para o controle de afídeos, cochonilhas e mosca-branca está sendo bastante estudado e utilizado por ser de fácil obtenção e ser pouco poluente. Um dos trabalhos pioneiros utilizando sabão para controlar afídeos do gênero Aphis foi realizado por PINNOCK et al. (1974), com índices promissores de supressão. Sabões e detergentes podem ser eficientes no controle de insetos de corpo mole pois interferem no metabolismo celular, causando muitas vezes a ruptura da membrana, além de desidratação através da remoção da cutícula de cera, e também provocar a obstrução dos espiráculos, impedindo a respiração (WEINZIERL \& HENN 1991; ButTler et al. 1993; MENDOZA et al. 2004).

Os resultados obtidos no presente trabalho foram semelhantes ao de CYSNE et al. (2014), onde os autores obtiveram eficiências diferenciadas de acordo com a dose de detergente utilizada para controlar $A$. craccivora em feijão-caupi, chegando a valores superiores a $80 \%$ quando utilizada uma concentração de $4 \%$. CASTRO et al. (2019) testaram uma solução de detergente neutro a $10 \%$ em mudas de mogno (Swietenia macrophylla King) infestadas com cochonilhas da espécie Phenacoccus solenopsis Tinsley (Hemiptera: Pseudococcidae) e obtiveram resultados satisfatórios de controle nas plantas avaliadas.

Aphis craccivora é uma espécie polífaga (BLACKMAN \& EASTOP 2007) que já foi reportada em mais de 50 plantas de diversas famílias botânicas, especialmente em espécies da família Leguminosae (BLACKMAN \& EASTOP 2019). Este afídeo é uma praga importante em diversas culturas agrícolas, não só pelo seu hábito fitófago, mas também pela habilidade de transmitir mais de trinta viroses para várias plantas, e é uma das principais pragas em feijão-caupi (Silva et al. 2005). Até o presente momento não tem relato da associação dessa espécie com $D$. miscolobium. Portanto, por ser uma praga importante que ataca diversas culturas de interesse econômico, $A$. craccivora pode afetar negativamente o desenvolvimento inicial de $D$. miscolobium, podendo assim ser tornar um fator limitante para a produção de mudas da espécie na região do Cerrado. Com isso, o uso da solução de detergente neutro pode ser empregado como uma alternativa menos danosa ao meio ambiente e ao homem para o controle desse afídeo.

\section{AGRADECIMENTOS}

Os autores são gratos à Dra. A. L. B. G. Peronti pela identificação do afídeo.

\section{REFERÊNCIAS}

Abbott, WS, 1925. A method of computing the efectiveness of an insecticide. Journal of Economic Entomology, 18: 265-267. DOI: https://doi.org/10.1093/iee/18.2.265a.

Almeida, SP de, CEB Proença, SM Sano \& JF Ribeiro, 1998. Cerrado: espécies vegetais úteis. Planaltina: EMBRAPACPAC. 464 p.

Andrei, E, 2009. Compêndio de defensivos agrícolas: guia prático de produtos fitossanitários para uso agrícola. São Paulo: Andrei Editora. 1378 p.

Blackman, RL \& VF Eastop, 2007. Taxonomic Issues, p. 1-30. In: van Emden, H. F. \& R. Harrington (Eds.). Aphids as Crop Pests. Wallingford, Oxfordshire.

Blackman, RL \& VF Eastop, 2019. Aphids on the World's Plants. Available on: <http://www.aphidsonworldsplants.info $>$. Access in: 02 de julho de 2019.

\section{Suggestion citation:}

de Castro, MT \& SCL Montalvão, 2019. Ocorrência e controle do pulgãopreto, Aphis craccivora Koch (Hemiptera: Aphididae), em mudas de jacarandá-do-cerrado (Dalbergia miscolobium Benth.) com o uso de detergente neutro. EntomoBrasilis, 12 (3): 154-156.

Available on: doi:10.12741/ebrasilis.v12i3.865
Braz, VS, MF Kanegae \& AC Franco, 2000. Estabelecimento e desenvolvimento de Dalbergia miscolobium Benth. em duas fitofisionomias típicas dos cerrados do Brasil Central. Acta Botanica Brasilica, 14: 27-35. DOI: https://doi.org/10.1590/ S0102-33062000000100004.

Butler Jr, GD, TJ Henneberry, PA Stansly \& DJ Schuster, 1993. Insecticidal effects of selected soaps, oils and detergents on the sweetpotato whitefly (Homoptera: Aleyrodidae). Florida Entomologist, 76: 161-166. DOI: https://doi.org/10.2307/3496023.

Castro, MT, SCL Montalvão, ALBG Peronti \& RG Monnerat, 2019. Ocorrência da cochonilha Phenacoccus solenopsis Tinsley (Hemiptera: Pseudococcidae) em mudas de mogno (Swietenia macrophylla King). EntomoBrasilis, 12: 41-43. DOI: https://doi.org/10.12741/ebrasilis.v12i1.791.

Cysne, AQ, JVTA Costa \& E Bleicher, 2014. Atividade inseticida de detergentes neutros sobre pulgão preto em feijão caupi. Revista de Ciências Agroambientais, 12: 75-81.

Imenes, SDL, EC Bergmann, AM Faria \& WR Martins, 2002. Registro de alta infestação e efeito de soluções de sabão no controle da cochonilha Protopulvinaria pyriformis Cockerell, 1894 (Hemiptera, Coccidae) em Schefflera arboricola (Hayata) Merr. (Araliaceae). Arquivos do Instituto Biológico, 69: 59-62.

Marquis, RJ, IR Diniz \& HC Morais, 2001. Patterns and correlates of interspecific variation in foliar insect herbivory and pathogen attack in Brazilian cerrado. Journal of Tropical Ecology, 17: 127-148. DOI: https://doi.org/10.1017/ S0266467401001080.

Mendonça, RC, JM Felfili, BMT Walter, MC Silva Júnior, AV Rezende, TS Filgueiras, PE Nogueira \& CW Fagg, 2008. Flora vascular do Bioma Cerrado: checklist com 12.356 espécies. p. 423-1279. In: Sano, SM, SP Almeida \& JF Ribeiro (Eds.). Cerrado: ecologia e flora. Brasília, Embrapa Cerrados.

Mendoza, CP, RN Hernández, CL Cázares \& HG Hernández, 2004. Efectividad biológica de productos biodegradables para el control de la cochinilla silvestre Dactylopius opuntiae (Cockerell) (Homoptera: Dactylopiidae). Acta Zoológica Mexicana, 20: 99-106.

Pinnock, DE, RJ Brand, JE Milstead \& NF Coe, 1974. Suppression of populations of Aphis gossypii and A. spiraecola by soap sprays. Journal of Economic Entomology, 67: 783-784. DOI: https://doi.org/10.1093/iee/67.6.783.

Predevello, JA \& CJB Carvalho, 2006. Conservação do Cerrado brasileiro: o método pan-biogeográfico como ferramenta para a seleção de áreas prioritárias. Natureza \& Conservação, 4: 39-57.

Silva, PHS, JS Carneiro \& MAW Quinderé, 2005. Pragas, p. 369-402. In: Freire Filho, F.R., J.A.A. Lima \& V.Q. Ribeiro. Feijão caupi: Avanços tecnológicos. Ed. Embrapa: Embrapa Informação Tecnológica.

Silva-Júnior, MC, 2012. 100 árvores do cerrado: guia de campo. Brasília: Rede de Sementes do Cerrado. 304 p.

Sturza, VS, STB Dequech, SLO Machado, S Poncio, A Bolzan \& C Guths, 2011. Primeiro registro de Aphis craccivora Koch 1854 (Hemiptera: Aphididae) sobre plantas daninhas em Santa Maria, RS. Ciência Rural, 41: 1863-1866. DOI: https://doi.org/10.1590/s0103-84782011001100001.

Weinzierl, R \& T Henn, 1991. Alternatives in Insect Pest Management: Biological and biorational approaches. Illinois: North Central Regional Extension Publication 401: Univ. of Illinois at Urbana-Champaign, $73 \mathrm{p}$.
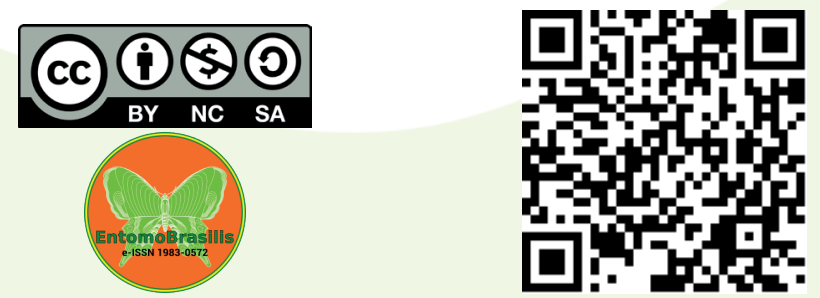